ORIGINAL ARTICLE

\title{
Reductions in pre-season training loads reduce training injury rates in rugby league players
}

\section{T J Gabbett}

Br J Sports Med 2004;38:743-749. doi: 10.1136/bjsm.2003.008391

See end of article for author's affiliation

.....................

Correspondence to: Dr Tim Gabbett, Queensland Academy of Sport, PO Box 956 Sunnybank, QLD 4109, Australia; tim.gabbett@ qld.gov.au

Accepted

30 September 2003

\begin{abstract}
Objectives: To investigate if reductions in pre-season training loads reduced the incidence of training injuries in rugby league players, and to determine if the reductions in training loads compromised the improvements in physical fitness obtained during the pre-season preparation period.

Methods: A total of 220 sub-elite rugby league players participated in this 3 year prospective study. Players underwent measurements of speed, muscular power, and maximal aerobic power before and after three 4 month (December to March) pre-season preparation periods (2001-2003). A periodised skills and conditioning program was implemented, with training loads progressively increased in the general preparatory phase of the season (December to February) and reduced slightly in March in preparation for the competitive phase of the season. Training loads were calculated by multiplying the training session intensity by the duration of the training session. Following the initial season (2001), training loads were reduced through reductions in training duration (2002) and training intensity (2003). The incidence of injury was prospectively recorded over the three pre-season periods.

Results: The training loads for the 2002 and 2003 pre-season periods were significantly lower $(p<0.001)$ than those in 2001. The incidence of injury was significantly higher in the 2001 pre-season than the 2002 and 2003 pre-season periods. The increases in maximal aerobic power progressively improved across the three seasons with a 62-88\% probability that the 2002 and 2003 pre-season improvements in maximal aerobic power were of greater physiological significance than the 2001 pre-season improvements in maximal aerobic power.

Conclusions: These findings demonstrate that reductions in pre-season training loads reduce training injury rates in rugby league players and result in greater improvements in maximal aerobic power.
\end{abstract}

$\mathrm{R}$ ugby league is an international collision sport played at amateur, ${ }^{12}$ semi-professional, ${ }^{3}{ }^{4}$ and professional levels. ${ }^{5-8}$ The game is physically demanding requiring players to compete in a challenging contest involving frequent bouts of high intensity activity such as running, passing, and sprinting, separated by short bouts of low intensity activity such as walking and jogging. ${ }^{9}$ During a match, players are exposed to numerous physical collisions and tackles. ${ }^{8}{ }^{10}$ As a result, musculoskeletal injuries are common. ${ }^{11}{ }^{12}$

While several studies have documented the incidence of rugby league playing injuries, ${ }^{5-7}{ }^{10-16}$ training injuries in rugby league have received relatively little attention. ${ }^{18}$ Recent evidence has shown that the majority of rugby league training injuries occur in the pre-season preparation period (December to March) when training loads are greatest. ${ }^{18}$ Indeed, the pre-season incidence of injury of 116.1 per 1000 training hours is 2.6-fold higher than the seasonal average injury rate (45.3 per 1000). ${ }^{14}$ Moreover, increases in training loads are significantly correlated $(r=0.86)$ with increases in training injury rates. ${ }^{18}$ These findings suggest that the harder rugby league players train, the more injuries they will sustain and that reductions in training loads will reduce training injury rates in these athletes. However, due to the physical nature of the sport, rugby league training sessions require an adequate intensity in order to develop the required physical qualities needed to compete optimally for the duration of a match. Therefore, reductions in training loads could minimise the pre-season improvements in physical fitness that are required for the forthcoming playing season.

Effective prevention of sporting injuries is dependent on the identification of the extent of the injury problem and the causes of injury, the implementation of injury prevention strategies, and the re-evaluation of the extent of the injury problem. ${ }^{19}$ While several studies have documented the extent of the injury problem in rugby league, an evidence based injury prevention program has not been implemented for this sport. With this in mind, the purpose of the present study was to investigate if reductions in pre-season training loads reduced the incidence of training injuries in rugby league players. In addition, a secondary purpose of this study was to determine if the reductions in training loads compromised the improvements in physical fitness obtained during the pre-season preparation period.

\section{METHODS}

A total of 220 healthy men, registered with the same sub-elite rugby league club participated in this 3 year prospective study (2001-2003). The total number of registered players over the 3 year period was 79, 65, and 76, respectively. Eleven $(5.0 \%)$ players played two or more seasons. All players were competing within the Gold Coast Group 18 (New South Wales Country Rugby League, Australia) (2001-2002) or South-East Queensland (Queensland Rugby League, Australia) (2003) senior rugby league competitions. Each pre-season training period lasted from December through March, with the competitive season lasting from March through September. All players underwent fitness testing in December and March as part of their pre-season training program.

\section{Fitness testing battery}

Muscular power (vertical jump), ${ }^{20}$ speed $(10 \mathrm{~m}, 20 \mathrm{~m}$, and $40 \mathrm{~m}$ sprint), ${ }^{21}$ and maximal aerobic power (multi-stage

Abbreviations: MCID, minimum clinically important difference; RPE, rating of perceived exertion 
fitness test $)^{22}$ were the fitness tests selected. The age and playing experience of players was also documented. Players were instructed to refrain from strenuous exercise for at least $48 \mathrm{~h}$ prior to the fitness testing session and consume their normal pre-training diet prior to each testing session. At the beginning of the fitness testing session, players underwent a standardised warm up (progressing from low to higher intensity activity) and stretching routine. Players performed two trials for the speed and muscular power tests, with a recovery of approximately $3 \mathrm{~min}$ between trials. Players were encouraged to perform low intensity activities and stretches between trials. Upon completion of the speed and muscular power tests, the field testing session was concluded with players performing the multi-stage fitness test (estimated maximal aerobic power).

\section{Muscular power}

Lower leg muscular power was evaluated by means of the vertical jump test. ${ }^{20}$ Vertical jump height was calculated as the distance between the highest point reached during standing and the highest point reached during the vertical jump. Vertical jump height was measured to the nearest $1 \mathrm{~cm}$ with the highest value obtained from two trials used as the vertical jump score. The intraclass correlation coefficient for test-retest reliability and typical error of measurement for the vertical jump test was 0.96 and $3.3 \%$, respectively.

\section{Speed}

The running speed of players was evaluated with a $10 \mathrm{~m}$, $20 \mathrm{~m}$, and $40 \mathrm{~m}$ sprint effort ${ }^{21}$ using dual beam electronic timing gates (Speed Light Model TB4, Serial No. 4921001; Southern Cross University Technical Services, Lismore, Australia). Speed was measured to the nearest $0.01 \mathrm{~s}$ with the fastest value obtained from two trials used as the speed score. The intraclass correlation coefficient for test-retest reliability and typical error of measurement for the $10 \mathrm{~m}$, $20 \mathrm{~m}$, and $40 \mathrm{~m}$ sprint tests were $0.95,0.97$, and 0.97 , and $1.8 \%, 1.3 \%$, and $1.2 \%$, respectively.

\section{Maximal aerobic power}

The multi-stage fitness test was used to estimate maximal aerobic power $\left(\dot{\mathrm{V}}_{2 \max }\right){ }^{22}{ }^{23}$ A correlation of 0.92 has been reported between the level achieved during the multi-stage fitness test and treadmill determined $\dot{\mathrm{V}}_{2 \text { max }}{ }^{23}$ In addition, all players completed duplicate multi-stage fitness tests, performed 1 week apart, prior to the commencement of this study to determine test-retest reliability. The intraclass correlation coefficient for test-retest reliability and typical error of measurement for the multi-stage fitness test were 0.90 and $3.1 \%$, respectively.

\section{Training loads}

Each player participated in two organised field training sessions per week. A periodised, game specific training program was implemented, with training loads progressively increased in the general preparatory phase of the season (December to February), and reduced slightly in March in preparation for the competitive phase of the season. The duration of training sessions was recorded, with sessions typically lasting between 60 and $100 \mathrm{~min}$. Players participated in 30 pre-season training sessions each year. Based on the finding that training injury rates are increased with increases in training loads, ${ }^{18}$ following the initial season (2001), training loads were reduced through reductions in training duration (2002) and training intensity (2003).

The intensity of individual training sessions was estimated using a modified rating of perceived exertion (RPE) scale. ${ }^{24}$ Training loads were calculated by multiplying the training session intensity by the duration of the training session.
Intensity estimates were obtained within 30 min of completing the training session. In the present study, the correlation between training heart rate and training RPE, and training blood lactate concentration and training RPE was 0.89 and 0.86 , respectively. A subset of players $(n=11)$ also completed two identical off-season training sessions, performed l week apart, prior to the commencement of the study to determine the test-retest reliability of the RPE scale. The intraclass correlation coefficient for test-retest reliability and typical error of measurement for the RPE scale were 0.99 and $4.0 \%$, respectively.

\section{Environmental conditions}

Daily weather variables were prospectively measured by the Bureau of Meteorology. Environmental data were taken from the nearest meteorology station (Southport, Queensland, Australia) to the location studied. Maximum, minimum, and average temperature, relative humidity, and rainfall were the environmental variables recorded. Given that a low annual rainfall has been shown to be a significant predictor of injury, ${ }^{25}$ the 365 day rainfall prior to the commencement of the pre-season training periods was also recorded.

\section{Definition of injury}

A head trainer, employed by the club to provide injury prevention and management services, and skills and conditioning coaching, assessed all injuries. The head trainer held tertiary qualifications in exercise and sport science and was nationally accredited in injury prevention, assessment, and management. For the purpose of this study, an injury was defined as any pain or disability suffered by a player during a training session, and subsequently assessed by the head trainer during, or immediately following, the training session. ${ }^{17}$ All injuries sustained during training sessions were recorded. The severity of injury was classified as transient (no training missed), minor (one training week missed), moderate (two to four training weeks missed), or major (five or more training weeks missed). ${ }^{11}{ }^{17}$

\section{Classification of injury}

Injuries were categorised according to the site of injury. The head and neck, face, abdomen and thorax, shoulder, arm and hand, thigh and calf, knee, ankle and foot, and "others" categories were the sites selected. Injuries were also described according to the type (nature) of injury sustained. Muscular injuries were classified as either haematomas or muscular strains. Additional categories for the type of injury included joint sprains, concussion, contusions, abrasions, blisters, lacerations, fractures and dislocations, and "others". Finally, injuries were described according to the cause of injury. Causes of injury were categorised as being tackled, while tackling, being struck by another player or ball, collision with another player or fixed object (for example, goal post, ground), fall/stumble (for example, rolling ankle while running), slip/trip (for example, slipping on wet surface), twisting to pass or accelerate, scrum contact, overexertion (for example, due to rapid changes in speed, intensity, and/or direction), overuse (for example, due to repetitive loading), temperature related disorders (for example, heat stress), and "others".

\section{Statistical analysis}

Differences in the age and playing experience of players, and environmental conditions were determined using a one way analysis of variance. Changes in muscular power, speed, $\dot{\mathrm{V}}_{2 \text { max }}$, and training loads over the three pre-season preparation periods were compared using a two way (season $\times$ month) analysis of variance and by comparing the true change in performance with the minimum clinically 
Table 1 Age and playing experience of sub-elite rugby league players

\begin{tabular}{llll}
\hline & 2001 & 2002 & 2003 \\
\hline Age (years) & $22.9(20.7$ to 25.1$)$ & $19.6(18.4$ to 20.8$)$ & $21.5(19.6$ to 23.4$)$ \\
Playing experience (years) & $16.7(13.5$ to 19.9) & $11.4(10.0$ to 12.8)* & $9.7(7.3$ to 12.0) \\
\hline
\end{tabular}

Values are reported as means $(95 \% \mathrm{Cl}) . \mathrm{Cl}$, confidence interval.

*Significantly different $(p<0.05)$ from the 2001 season.

important difference (MCID) for that variable. ${ }^{26}$ The MCID was defined as the smallest worthwhile change perceived to be physiologically significant to the average athlete. The MCID for muscular power, $40 \mathrm{~m}$ speed, and $\dot{\mathrm{V}}_{2 \max }$ was calculated as $1.5 \mathrm{~cm}, 0.10 \mathrm{~s}$, and $0.8 \mathrm{ml} \mathrm{kg} \mathrm{min}^{-1}$, respectively. Injury exposure was calculated by multiplying the number of players by the session duration. Injury rates were calculated by dividing the total number of injuries by the overall training injury exposure. Expected injury rates were calculated as described by Hodgson Phillips et al. ${ }^{12}$ The chi-squared $\left(\chi^{2}\right)$ test was used to determine whether the observed injury frequency was significantly different from the expected injury frequency. All data were reported as means and 95\% confidence intervals (CI) and the level of significance was set at $\mathrm{p}<0.05$.

\section{RESULTS}

\section{Age and playing experience}

The age and playing experience of the players are shown in table 1. Players in the 2001 season had significantly greater $(\mathrm{p}<0.05)$ playing experience than those in the 2002 and 2003 seasons.

\section{Environmental conditions}

There were no significant differences $(\mathrm{p}>0.05)$ among preseason periods for the recorded maximum, minimum, and average temperature, and relative humidity. The average rainfall for the 2002 pre-season period $(73.9 \mathrm{~mm}, 95 \% \mathrm{CI}$ : 35.7 to 112.0 ) was lower than the average rainfall for the 2001 ( $184.5 \mathrm{~mm}, 95 \%$ CI: 99.0 to 269.9) and 2003 ( $181.3 \mathrm{~mm}$, 95\% CI: 0.0 to 378.5 ) pre-season periods. The 365 day rainfall prior to the commencement of the pre-season training period was not significantly different $(p>0.05)$ among seasons.

\section{Training loads}

There were significant differences among seasons for training intensity, training duration, and training loads. The training intensity in the 2003 pre-season was significantly lower $(\mathrm{p}<0.01)$ than the 2001 pre-season. There were no significant differences between the 2001 pre-season (4.20 units, 95\% CI: 4.09 to 4.32 ) and the 2002 pre-season (4.05 units, 95\% CI: 3.89 to 4.22 ) or the 2002 pre-season and the 2003 pre-season (3.90 units, 95\% CI: 3.75 to 4.05 ) for training intensity. Training duration was significantly higher $(\mathrm{p}<0.001)$ in the 2001 pre-season $(78.1 \mathrm{~min}, 95 \% \mathrm{CI}: 77.1$ to 79.1$)$ than the 2002 pre-season (67.9 $\mathrm{min}, 95 \% \mathrm{CI}$ : 66.8 to 68.9 ) and 2003
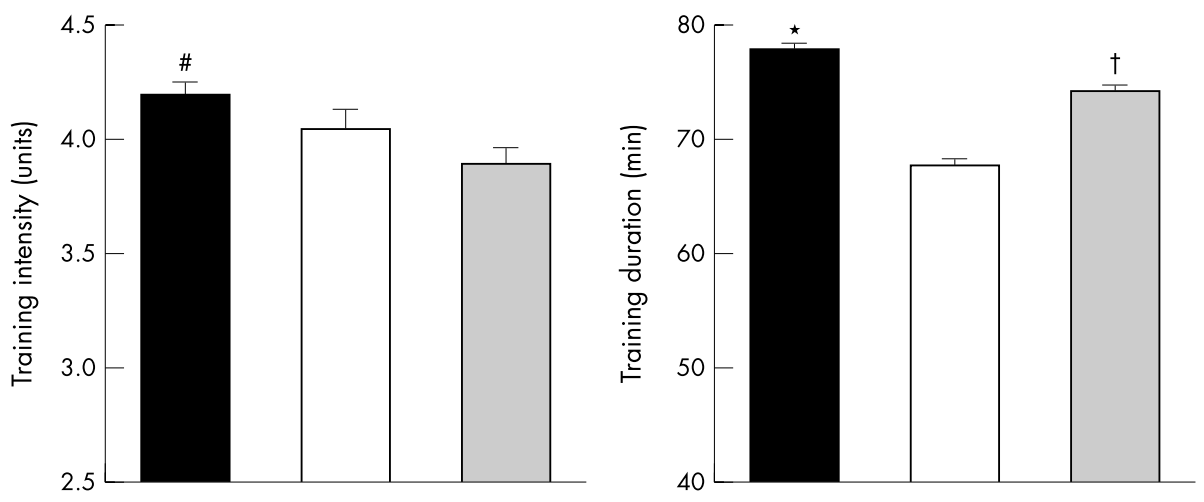

Figure 1 Overall training intensity, duration, and loads, and injury rates of sub-elite rugby league players over three consecutive pre-season preparation periods. Values are reported as means $(95 \% \mathrm{Cl})$. *Significantly different $(p<0.001)$ from 2002 and 2003 seasons. †Significantly different $(p<0.001)$ from 2002 season. \#Significantly different $(p<0.01)$ from 2003 season.
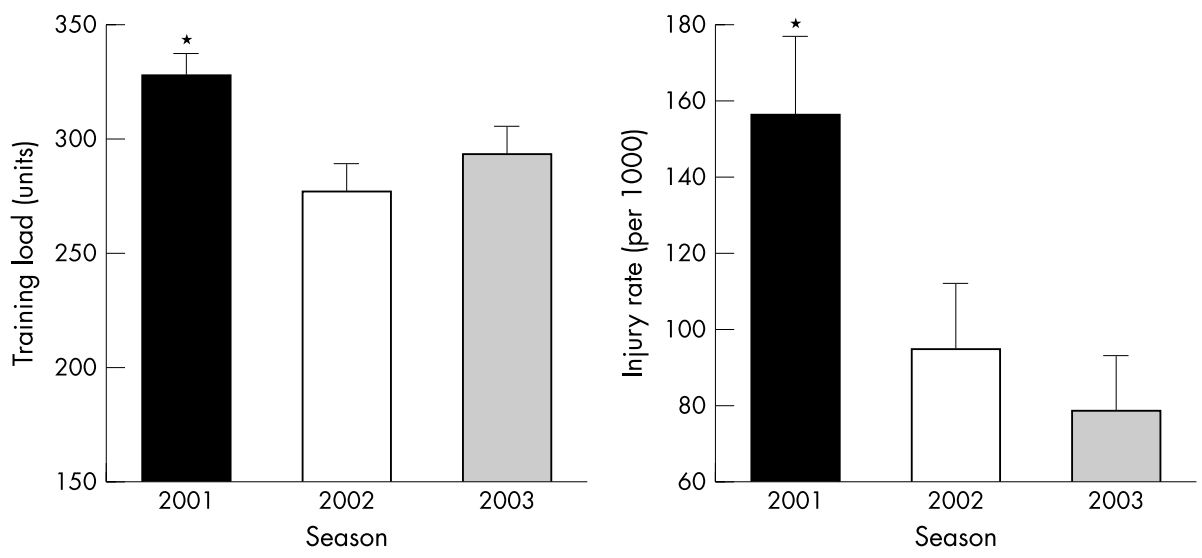
Table 2 Monthly training loads of sub-elite rugby league players over three consecutive pre-season preparation periods

\begin{tabular}{|c|c|c|c|c|c|c|c|c|c|}
\hline & \multicolumn{3}{|l|}{2001} & \multicolumn{3}{|l|}{2002} & \multicolumn{3}{|l|}{2003} \\
\hline & Intensity & Duration & Load & Intensity & Duration & Load & Intensity & Duration & Load \\
\hline December & $\begin{array}{l}4.7 \\
(4.4 \text { to } 5.0)\end{array}$ & $\begin{array}{l}59 \\
(57 \text { to } 61)\end{array}$ & $\begin{array}{l}278 \\
\text { (262 to } 294)\end{array}$ & $\begin{array}{l}4.0 \\
(3.6 \text { to } 4.4)\end{array}$ & $\begin{array}{l}58 \\
\text { (57 to } 59)\end{array}$ & $\begin{array}{l}237 \\
\text { (215 to } 259 \text { ) }\end{array}$ & $\begin{array}{l}3.5 \\
(3.3 \text { to } 3.7)\end{array}$ & $\begin{array}{l}62 \\
(61 \text { to } 63)\end{array}$ & $\begin{array}{l}221 \\
\text { (205 to } 236 \text { ) }\end{array}$ \\
\hline January & $\begin{array}{l}4.0 \\
(3.8 \text { to } 4.2)\end{array}$ & $\begin{array}{l}79 \\
(78 \text { to } 80)\end{array}$ & $\begin{array}{l}311 \\
\text { (297 to } 325)\end{array}$ & $\begin{array}{l}4.0 \\
(3.7 \text { to } 4.3)\end{array}$ & $\begin{array}{l}61 \\
\text { (60 to } 62 \text { ) }\end{array}$ & $\begin{array}{l}242 \\
(224 \text { to } 260)\end{array}$ & $\begin{array}{l}3.9 \\
(3.7 \text { to } 4.1)\end{array}$ & $\begin{array}{l}76 \\
\text { (75 to } 77)\end{array}$ & $\begin{array}{l}299 \\
\text { (281 to } 317)\end{array}$ \\
\hline February & $\begin{array}{l}4.4 \\
(4.2 \text { to } 4.6)\end{array}$ & $\begin{array}{l}86 \\
\text { (85 to } 87)\end{array}$ & $\begin{array}{l}385 \\
\text { (362 to } 408)\end{array}$ & $\begin{array}{l}4.3 \\
(4.0 \text { to } 4.6)\end{array}$ & $\begin{array}{l}77 \\
\text { (76 to } 78)\end{array}$ & $\begin{array}{l}338 \\
(315 \text { to } 361)\end{array}$ & $\begin{array}{l}4.0 \\
(3.7 \text { to } 4.4)\end{array}$ & $\begin{array}{l}83 \\
\text { (82 to } 84)\end{array}$ & $\begin{array}{l}336 \\
\text { (307 to } 365)\end{array}$ \\
\hline March & $\begin{array}{l}3.7 \\
(3.5 \text { to } 3.9)\end{array}$ & $\begin{array}{l}86 \\
\text { (85 to } 87)\end{array}$ & $\begin{array}{l}330 \\
(310 \text { to } 350)\end{array}$ & $\begin{array}{l}3.3 \\
(2.9 \text { to } 3.7)\end{array}$ & $\begin{array}{l}67 \\
\text { (64 to } 70)\end{array}$ & $\begin{array}{l}225 \\
\text { (198 to } 252)\end{array}$ & $\begin{array}{l}4.2 \\
(3.8 \text { to } 4.6)\end{array}$ & $\begin{array}{l}80 \\
\text { (78 to } 82 \text { ) }\end{array}$ & $\begin{array}{l}335 \\
(300 \text { to } 370)\end{array}$ \\
\hline
\end{tabular}

Values are reported as means $(95 \% \mathrm{Cl})$. $\mathrm{Cl}$, confidence interval.

pre-season (74.5 $\min , 95 \%$ CI: 73.7 to 75.3 ) period. The 2002 and 2003 pre-season training loads were significantly lower $(\mathrm{p}<0.001)$ than the 2001 pre-season training loads. There were no significant differences $(\mathrm{p}>0.05)$ between the 2002 and 2003 pre-season training loads (table 2, fig 1 ).

\section{Incidence of injury}

The overall injury exposure for the three pre-season periods was 1442.4 (2001), 1165.9 (2002), and 1478.9 (2003) training hours at risk. The incidence of injury was significantly higher $\left(\chi^{2}=44.3\right.$, df $\left.2, \mathrm{p}<0.001\right)$ in the 2001 pre-season period (156.7 per 1000 training hours, 95\% CI: 136.3 to 177.1 ) than the 2002 (94.4 per 1000 training hours, 95\% CI: 76.7 to 112.0 ) and 2003 (78.4 per 1000 training hours, 95\% CI: 64.2 to 92.7) pre-season periods. There were no significant differences in the incidence of injury between the 2002 and 2003 pre-season periods (table 3, fig 1).

\section{Site of injury}

The majority of injuries sustained over the three seasons were to the thigh and calf, ankle and foot, and knee. There were significant differences among seasons for injuries sustained to the thorax and abdomen $\left(\chi^{2}=14.6\right.$, df $\left.2, \mathrm{p}<0.001\right)$. The incidence of thigh and calf $\left(\chi^{2}=28.2\right.$, df $\left.2, p<0.001\right)$ and ankle and foot $\left(\chi^{2}=26.9\right.$, df $\left.2, p<0.001\right)$ injuries was significantly higher in the 2001 pre-season period than the 2002 and 2003 pre-season periods (table 4).

\section{Nature of injury}

The type of injuries sustained over the three seasons is shown in table 5. The majority of injuries sustained over the three seasons were muscular strains and joint sprains. The incidence of muscular strains $\left(\chi^{2}=44.6\right.$, df $\left.2, p<0.001\right)$, joint sprains $\left(\chi^{2}=17.0\right.$, df $\left.2, \mathrm{p}<0.001\right)$, and haematomas $\left(\chi^{2}=7.1\right.$, df $\left.2, p<0.05\right)$ was significantly higher in the 2001 pre-season period than the 2002 and 2003 pre-season periods.

\section{Cause of injury}

Overexertion was the most common cause of injury. There were significant differences among seasons for injuries sustained while being tackled $\left(\chi^{2}=6.4\right.$, df $\left.2, \mathrm{p}<0.05\right)$. Overexertion $\left(\chi^{2}=38.2\right.$, df $\left.2, \quad \mathrm{p}<0.001\right)$ and overuse $\left(\chi^{2}=11.1\right.$, df $\left.2, \mathrm{p}<0.01\right)$ injuries were more common in the 2001 pre-season period than the 2002 and 2003 pre-season periods (table 6).

\section{Severity of injury}

The majority of injuries were transient, resulting in no loss of training time. There were significantly more $\left(\chi^{2}=6.0\right.$, df 2 , $\mathrm{p}<0.05)$ severe injuries in the 2001 pre-season period $(33.3$

Table 3 Monthly injury rates of sub-elite rugby league players over three consecutive pre-season preparation periods

\begin{tabular}{|c|c|c|c|c|c|c|c|c|c|}
\hline & \multicolumn{3}{|l|}{2001} & \multicolumn{3}{|l|}{2002} & \multicolumn{3}{|l|}{2003} \\
\hline & Number & Rate & $95 \% \mathrm{Cl}$ & Number & Rate & $95 \% \mathrm{Cl}$ & Number & Rate & $95 \% \mathrm{Cl}$ \\
\hline December & 17 & 105.2 & 55.2 to 155.2 & 10 & 123.3 & 46.9 to 199.7 & 9 & 53.3 & 18.5 to 88.1 \\
\hline January & 56 & 183.5 & 135.4 to 231.6 & 32 & 107.4 & 70.2 to 144.6 & 34 & 98.8 & 65.6 to 132.0 \\
\hline February & 86 & 205.5 & 162.1 to 248.9 & 47 & 104.9 & 74.9 to 134.9 & 48 & 114.9 & 82.4 to 147.4 \\
\hline March & 67 & 120.2 & 91.4 to 149.0 & 21 & 62.0 & 35.5 to 88.5 & 25 & 45.6 & 27.7 to 63.5 \\
\hline
\end{tabular}

Values are reported as rates per 1000 training hours. $\mathrm{Cl}$, confidence interval.

Table 4 Site of training injuries sustained by sub-elite rugby league players over three consecutive pre-season preparation periods

\begin{tabular}{|c|c|c|c|c|c|c|c|c|c|}
\hline \multirow[b]{2}{*}{ Site of injury } & \multicolumn{3}{|l|}{2001} & \multicolumn{3}{|l|}{2002} & \multicolumn{3}{|l|}{2003} \\
\hline & Number & Rate & $95 \% \mathrm{Cl}$ & Number & Rate & $95 \% \mathrm{Cl}$ & Number & Rate & $95 \% \mathrm{Cl}$ \\
\hline Head/neck & 4 & 2.8 & 0.1 to 5.5 & 6 & 5.1 & 1.0 to 9.3 & 6 & 4.1 & 0.8 to 7.3 \\
\hline Face & 10 & 6.9 & 2.6 to 11.2 & 10 & 8.6 & 3.3 to 13.9 & 11 & 7.4 & 3.0 to 11.8 \\
\hline Thorax/abdomen & 30 & 20.8 & 13.4 to $28.2^{*}$ & 5 & 4.3 & 0.5 to 8.1 & 16 & 10.8 & 5.5 to 16.1 \\
\hline Shoulder & 6 & 4.2 & 0.8 to 7.5 & 2 & 1.7 & 0 to 4.1 & 2 & 1.4 & 0.0 to 3.2 \\
\hline Arm/hand & 10 & 6.9 & 2.6 to 11.2 & 9 & 7.7 & 2.7 to 12.8 & 16 & 10.8 & 5.5 to 16.1 \\
\hline Thigh/calf & 78 & 54.1 & 42.1 to $66.1^{*}$ & 38 & 32.6 & 22.2 to 43.0 & 26 & 17.6 & 10.8 to 24.3 \\
\hline Knee & 25 & 17.3 & 10.5 to 24.1 & 14 & 12.0 & 5.7 to 18.3 & 17 & 11.5 & 6.0 to 17.0 \\
\hline Ankle/foot & 62 & 43.0 & 32.3 to $53.7^{*}$ & 23 & 19.7 & 11.7 to 27.8 & 20 & 13.5 & 7.6 to 19.5 \\
\hline Other & 1 & 0.7 & 0.0 to 2.1 & 3 & 2.6 & 0.0 to 5.5 & 2 & 1.4 & 0.0 to 3.2 \\
\hline
\end{tabular}

Values are reported as rates per 1000 training hours. $\mathrm{Cl}$, confidence interval.

*Significant differences $(p<0.05)$ among 2001, 2002, and 2003 seasons. 
Table 5 Nature of training injuries sustained by sub-elite rugby league players over three consecutive pre-season preparation periods

\begin{tabular}{|c|c|c|c|c|c|c|c|c|c|}
\hline \multirow[b]{2}{*}{ Nature of injury } & \multicolumn{3}{|l|}{2001} & \multicolumn{3}{|l|}{2002} & \multicolumn{3}{|l|}{2003} \\
\hline & Number & Rate & $95 \% \mathrm{Cl}$ & Number & Rate & $95 \% \mathrm{Cl}$ & Number & Rate & $95 \% \mathrm{Cl}$ \\
\hline Muscular strains & 90 & 62.4 & 49.5 to $75.3^{*}$ & 27 & 23.2 & 14.4 to 31.9 & 29 & 19.6 & 12.5 to 26.8 \\
\hline Joint sprains & 50 & 34.7 & 25.1 to $44.3^{*}$ & 17 & 14.6 & 7.7 to 21.5 & 22 & 14.9 & 8.7 to 21.1 \\
\hline Blisters & 20 & 13.9 & 7.8 to 19.9 & 7 & 6.0 & 1.6 to 10.5 & 11 & 7.4 & 3.0 to 11.8 \\
\hline Abrasions & 18 & 12.5 & 6.7 to 18.2 & 24 & 20.6 & 12.4 to 28.8 & 20 & 13.5 & 7.6 to 19.5 \\
\hline Contusions & 18 & 12.5 & 6.7 to 18.2 & 18 & 15.4 & 8.3 to 22.6 & 16 & 10.8 & 5.5 to 16.1 \\
\hline Haematomas & 11 & 7.6 & 3.1 to $12.1^{*}$ & 4 & 3.4 & 0.1 to 6.8 & 2 & 1.4 & 0.0 to 3.2 \\
\hline Fractures/dislocations & 2 & 1.4 & 0.0 to 3.3 & 1 & 0.9 & 0.0 to 2.5 & 3 & 2.0 & 0.0 to 4.3 \\
\hline Lacerations & 1 & 0.7 & 0.0 to 2.1 & 1 & 0.9 & 0.0 to 2.5 & 3 & 2.0 & 0.0 to 4.3 \\
\hline Concussions & - & - & - & 2 & 1.7 & 0.0 to 4.1 & 1 & 0.7 & 0.0 to 2.0 \\
\hline Other & 16 & 11.1 & 5.7 to 16.5 & 9 & 7.7 & 2.7 to 12.8 & 9 & 6.1 & 2.1 to 10.1 \\
\hline
\end{tabular}

Values are reported as rates per 1000 training hours. $\mathrm{Cl}$, confidence interval.

*Significant differences $(p<0.05)$ among 2001,2002 , and 2003 seasons.

per 1000 training hours, $95 \%$ CI: 23.9 to 42.7 ) than the 2002 (30.0 per 1000 training hours, 95\% CI: 20.0 to 40.0 ) and 2003 (18.9 per 1000 training hours, 95\% CI: 11.9 to 25.9 ) preseason periods (table 7 ).

\section{Changes in physical fitness}

The changes in speed, muscular power, and $\dot{V}_{2}$ max over the three pre-season periods are shown in table 8 . The pretraining muscular power and $\dot{\mathrm{V}}_{2 \max }$ were similar $(\mathrm{p}>0.05)$ across the three pre-season periods. Pre-training speed measurements $(10 \mathrm{~m}, 20 \mathrm{~m}$, and $40 \mathrm{~m}$ sprint) were significantly faster $(\mathrm{p}<0.05)$ in the 2003 pre-season. There were no significant $(p>0.05)$ seasonal differences for changes in $10 \mathrm{~m}, 20 \mathrm{~m}$, and $40 \mathrm{~m}$ speed. There were greater improvements in muscular power in the 2003 pre-season period, with a $76 \%$ probability that the improvements were of physiological significance. Each pre-season training period induced a significant increase $(\mathrm{p}<0.05)$ in $\dot{\mathrm{V}}_{2 \max }$. The increases in $\dot{V}_{\mathrm{O}_{2 \max }}$ progressively improved across the three seasons $(2001,7.7 \% ; 2002,11.8 \% ; 2003,15.6 \%)$, with a $62-88 \%$ probability that the 2002 and 2003 pre-season improvements in $\dot{V}_{\mathrm{O}_{2} \max }$ were of greater physiological significance than the 2001 pre-season improvements in $\dot{\mathrm{V}}_{2 \max }$.

\section{DISCUSSION}

This study is the first to concurrently investigate training loads, changes in physical fitness, and training injury rates in rugby league players. In addition, this study is the first to implement and evaluate the effectiveness of an evidence based injury prevention program for rugby league players. The results of this study are of particular importance given that the greatest training injury rates have been shown to occur in the pre-season preparation period ${ }^{15}{ }^{18}$ and that the pre-season preparation period is where the greatest changes in physical fitness can be expected to occur. These findings demonstrate that reductions in pre-season training loads reduce training injury rates in rugby league players and result in greater improvements in maximal aerobic power.

In the present study, reductions in training loads were accomplished through reductions in training duration in the 2002 pre-season and training intensity in the 2003 preseason. Both changes to the training program elicited reductions in training injury rates. A $10.6-15.7 \%$ reduction in training loads reduced the incidence of injury by 39.8$50.0 \%$, without compromising the pre-season improvements in physical fitness. Indeed, there was a greater relative change in $\dot{\mathrm{V}}_{2 \max }$ with reduced training loads (2001, 7.7\%; $2002,11.8 \% ; 2003,15.6 \%)$. It is generally acknowledged that the greatest improvements in physical fitness occur in athletes with the lowest initial fitness level. ${ }^{27}$ Therefore, the greater relative changes in $\dot{\mathrm{V}}_{2 \max }$ over the three pre-season periods could possibly be explained by the slightly lower pretraining $\dot{\mathrm{V}}_{2 \max }$ of players in the 2002 and 2003 pre-season periods. Alternatively, the greater improvements in $\dot{\mathrm{V}}_{\mathrm{O}_{2 \max }}$ in the latter seasons may be due to the lower incidence and severity of injuries in this period, thereby allowing players to participate in a greater number of training sessions than the 2001 pre-season. The lack of significant differences in injury rates between the 2002 and 2003 pre-season periods suggests that reductions in training intensity and training duration are equally effective in reducing training injury rates. It is unclear if greater reductions in either training intensity or training duration would further reduce training injury rates. It is also unclear whether further reductions in injury rates may occur through concomitant reductions in both training duration and training intensity. Given the low incidence of injury and the large improvements in $\dot{\mathrm{V}}_{2 \max }$ in the 2003 pre-season period, it is possible that further reductions in training load

Table 6 Cause of training injuries sustained by sub-elite rugby league players over three consecutive pre-season preparation periods

\begin{tabular}{|c|c|c|c|c|c|c|c|c|c|}
\hline \multirow[b]{2}{*}{ Cause of injury } & \multicolumn{3}{|l|}{2001} & \multicolumn{3}{|l|}{2002} & \multicolumn{3}{|l|}{2003} \\
\hline & Number & Rate & $95 \% \mathrm{Cl}$ & Number & Rate & $95 \% \mathrm{Cl}$ & Number & Rate & $95 \% \mathrm{Cl}$ \\
\hline Overexertion & 90 & 62.4 & 49.5 to $75.3^{*}$ & 26 & 22.3 & 13.7 to 30.9 & 36 & 24.3 & 16.4 to 32.3 \\
\hline Overuse & 47 & 32.6 & 23.3 to $41.9^{*}$ & 22 & 18.9 & 11.0 to 26.8 & 22 & 14.9 & 8.7 to 21.1 \\
\hline Contact with player/object & 31 & 21.5 & 13.9 to 29.1 & 27 & 23.2 & 14.4 to 31.9 & 24 & 16.2 & 9.7 to 22.7 \\
\hline Fall/stumble & 27 & 18.7 & 11.7 to $25.8^{*}$ & 11 & 9.4 & 3.9 to 15.0 & 8 & 5.4 & 1.7 to 9.2 \\
\hline Ground contact & 16 & 11.1 & 5.7 to 16.5 & 16 & 13.7 & 7.0 to 20.5 & 13 & 8.8 & 4.0 to 13.6 \\
\hline Being tackled & 2 & 1.4 & 0.0 to $3.3^{*}$ & 1 & 0.9 & 0.0 to 2.5 & 8 & 5.4 & 1.7 to 9.2 \\
\hline While tackling & 1 & 0.7 & 0.0 to 2.1 & 2 & 1.7 & 0.0 to 4.1 & 4 & 2.7 & 0.1 to 5.4 \\
\hline Other & 12 & 8.3 & 3.6 to $13.0^{*}$ & 5 & 4.3 & 0.5 to 8.1 & 1 & 0.7 & 0.0 to 2.0 \\
\hline
\end{tabular}

Values are reported as rates per 1000 training hours. $\mathrm{Cl}$, confidence interval.

*Significant differences ( $p<0.05)$ among 2001, 2002, and 2003 seasons. 
Table 7 Severity of training injuries sustained by sub-elite rugby league players over three consecutive pre-season preparation periods

\begin{tabular}{|c|c|c|c|c|c|c|c|c|c|}
\hline \multirow{2}{*}{$\begin{array}{l}\text { Severity of } \\
\text { injury }\end{array}$} & \multicolumn{3}{|l|}{2001} & \multicolumn{3}{|l|}{2002} & \multicolumn{3}{|l|}{2003} \\
\hline & Number & Rate & $95 \% \mathrm{Cl}$ & Number & Rate & $95 \% \mathrm{Cl}$ & Number & Rate & $95 \% \mathrm{Cl}$ \\
\hline Transient & 178 & 123.4 & 105.3 to $141.5^{*}$ & 75 & 64.3 & 49.8 to 78.9 & 88 & 59.5 & 47.1 to 71.9 \\
\hline Minor & 44 & 30.5 & 21.5 to $39.5^{*}$ & 33 & 28.3 & 18.7 to 38.0 & 22 & 14.9 & 8.7 to 21.1 \\
\hline Moderate & 3 & 2.1 & 0.0 to 4.4 & 2 & 1.7 & 0.0 to 4.1 & 5 & 3.4 & 0.4 to 6.3 \\
\hline Major & 1 & 0.7 & 0.0 to 2.1 & - & - & - & 1 & 0.7 & 0.0 to 2.0 \\
\hline
\end{tabular}

Values are reported as rates per 1000 training hours. $\mathrm{Cl}$, confidence interval.

*Significant differences $(p<0.05)$ among 2001, 2002, and 2003 seasons.

may reduce training injury rates but also minimise the improvements in physical fitness obtained during the preseason preparation period. The obvious challenge for rugby league conditioning coaches is to develop training programs that provide an adequate training stimulus to enhance physical fitness, without unduly increasing the incidence of training injuries. Further studies investigating the effect of reductions in both training intensity and training duration on training injury rates and physical fitness are warranted.

In the present study, reductions in training loads were associated with reductions in lower limb injuries, muscular strains, and joint sprains. In addition, overuse injuries and injuries sustained as a result of overexertion were less common following the reductions in training loads. Overtraining is associated with a high incidence of overuse injuries $^{28}$ and compromised aerobic fitness. ${ }^{29}$ Given the high incidence of lower limb overuse injuries and smaller increases in $\dot{\mathrm{V}}_{2 \max }$ in the 2001 pre-season, it is likely that these players were over-trained, and that the training loads applied were greater than was tolerable for the musculoskeletal system. While the absolute training loads applied in the 2001 preseason period were unlikely to pose a significant training stimulus for elite rugby league players or players with a greater training history, it is possible that the applied training program limited the opportunity for adequate recovery for the players training in the 2001 pre-season period. Furthermore, the higher intensity, longer duration training sessions undertaken in the 2001 pre-season period may provide some explanation for the high incidence of thigh and calf strains and greater injury severity during this period.

Age $^{30}$ playing experience, ${ }^{31}$ and previous injury ${ }^{30}$ have been shown to be risk factors for subsequent sporting injury. The finding of greater age and playing experience in the players of the 2001 season may therefore offer an explanation for the higher injury rates in this cohort. In addition, given the greater playing experience of the players in the 2001 season, it is likely that they had also sustained more injuries prior to the commencement of the study. The higher incidence of injury during the 2001 pre-season preparation period may reflect a greater risk of injury due to previous injuries sustained while participating in rugby league.

Previous studies of collision sports (Australian football) have shown that a low rainfall is a significant predictor of injury, and that injury rates are reduced when rainfall is high. ${ }^{25}$ The present study found a similar rainfall in the 2001 and 2003 pre-season periods, but a considerably lower rainfall in the 2002 pre-season period. In contrast to previous findings ${ }^{25}$ the incidence of injury was significantly reduced when rainfall was lowest (2002 pre-season period), and remained low when rainfall returned to similar values to those obtained during the 2001 pre-season. Given the similar rainfall between the 2001 and 2003 pre-season periods, the lower rainfall in the 2002 pre-season period, and the marked differences in injury rates, it is unlikely that rainfall influenced the incidence of injury in the present study. The reason for the different findings between the present and previous studies ${ }^{25}$ is unclear but may be due to the duration of the studies, with the present investigation spanning a 4 month pre-season period, and previous investigations spanning an entire playing season. Further studies are required to determine the relationship between environmental conditions (particularly rainfall) and injury rates in rugby league over an entire playing season.

The present findings provide the expected changes in physical fitness from a 4 month pre-season conditioning program in sub-elite rugby league players. These findings demonstrate that sub-elite rugby league players undertaking a progressively overloaded training program, performing two sessions per week, may expect a $7.5-15.9 \%$ increase in aerobic fitness, and stable $10 \mathrm{~m}, 20 \mathrm{~m}$, and $40 \mathrm{~m}$ speed. The improvements in $\dot{V}_{O_{2 m a x}}$ are higher than the $1.9-3.0 \%$ improvement in $\dot{\mathrm{V}}_{2}$ max previously reported for elite rugby union players, ${ }^{32}{ }^{33}$ and similar to that previously reported $(10.2 \%)$ for elite soccer players ${ }^{34}$ following a similar period of pre-season conditioning. In addition, the $5.7 \%$ improvement in vertical jump scores during the 2003 pre-season period was well above the typical error of measurement of 3.3\%, therefore offering players a physiologically significant

Table 8 Pre-training and post-training measurements of muscular power, maximal aerobic power, and $10 \mathrm{~m}, 20 \mathrm{~m}$, and $40 \mathrm{~m}$ speed of sub-elite rugby league players over three consecutive pre-season preparation periods

\begin{tabular}{|c|c|c|c|c|c|c|}
\hline & \multicolumn{2}{|l|}{2001} & \multicolumn{2}{|l|}{2002} & \multicolumn{2}{|l|}{2003} \\
\hline & Pre-training & Post-training & Pre-training & Post-training & Pre-training & Post-training \\
\hline $10 \mathrm{~m}(\mathrm{~s})$ & $2.24(2.17$ to 2.31$) \dagger$ & 2.22 (2.15 to 2.29$) \dagger$ & 2.15 (2.09 to 2.21$) \dagger$ & $2.18(2.15$ to 2.21$) \dagger$ & 1.83 (1.77 to 1.89$)$ & $1.85(1.81$ to 1.89$)$ \\
\hline $20 \mathrm{~m}(\mathrm{~s})$ & $3.55(3.44$ to 3.66$) t$ & $3.54(3.45$ to 3.63$) \dagger$ & $3.49(3.43$ to 3.55$) \dagger$ & $3.50(3.45$ to 3.55$) \dagger$ & 3.15 (3.05 to 3.25$)$ & $3.12(3.05$ to 3.19$)$ \\
\hline $40 \mathrm{~m}(\mathrm{~s})$ & $6.09(5.99$ to 6.19$) \dagger$ & 6.05 (5.92 to 6.18)† & $5.98(5.89$ to 6.07$) \dagger$ & $5.98(5.88$ to 6.08$) \dagger$ & 5.61 (5.43 to 5.79$)$ & $5.61(5.48$ to 5.74$)$ \\
\hline $\begin{array}{l}\text { Vertical jump } \\
(\mathrm{cm})\end{array}$ & $53.1(50.3$ to 55.9$)$ & 53.3 (50.8 to 55.8 ) & $54.6(52.1$ to 57.1$)$ & $54.2(52.1$ to 56.3$)$ & 55.4 (52.0 to 58.8$)$ & 58.6 (56.0 to 61.2 ) \\
\hline $\begin{array}{l}\mathrm{V}_{2 \max } \\
\mathrm{ml} / \mathrm{kg} / \mathrm{min}\end{array}$ & 43.8 (41.5 to 46.1$)$ & $47.2(45.1 \text { to } 49.3)^{*}$ & 40.7 (37.2 to 44.2 ) & $45.5(43.4 \text { to } 47.6)^{*}$ & 42.0 (38.8 to 45.2 ) & 48.5 (46.1 to 50.9$)^{*}$ \\
\hline
\end{tabular}




\section{What is already known on this topic}

The majority of rugby league training injuries occur in the pre-season preparation period when training loads are greatest.

\section{What this study adds}

This study found that reductions in pre-season training loads reduce training injury rates in rugby league players and result in greater improvements in maximal aerobic power.

increase in muscular power. As only two training sessions were performed each week, with training sessions generally no longer than $90 \mathrm{~min}$ in duration, it was difficult to train all physiological fitness parameters effectively and also enhance skill. It is unclear if greater improvements in the physiological capacities of players would have occurred if a larger amount of training time was devoted to the development of specific performance parameters (for example, aerobic fitness, muscular power, and speed). Equally, it is unclear if further improvements in $\dot{\mathrm{V}}_{2 \max }$, muscular power, and speed would have occurred during the competitive phase of the season, when players were required to contend with injuries and residual fatigue. ${ }^{32}$ Future studies documenting the training loads and seasonal changes in the physiological performance characteristics of rugby league players are clearly required.

Due to limited resources (for example, video analysis, match statistics), it was not possible to analyse playing performance (for example, distance covered during a match, number of involvements with and without the ball, average work intensity during a match, etc) in the present study. While playing performance was not recorded, the win-loss ratio declined over the three seasons and coincided with the reductions in training loads. These results suggest that reductions in training loads may be associated with reductions in playing performance. However, the playing experience of the subjects also declined over the 3 year period (table 1). It has previously been shown that playing experience is a significant predictor of successful rugby league performance. ${ }^{3}$ Therefore, the lower playing experience of subjects in the 2002 and 2003 seasons may explain the reduction in playing performance (as evidenced from the win-loss ratio) during this period. Clearly, further studies investigating the effect of reductions in training loads on playing performance are warranted.

In summary, the present study investigated if reductions in pre-season training loads reduced the incidence of training injuries in rugby league players and determined if the reductions in training loads compromised the improvements in physical fitness obtained during the pre-season preparation period. The results of this study demonstrate that reductions in pre-season training loads reduce training injury rates in rugby league players and result in greater improvements in maximal aerobic power. Further studies investigating the influence of reductions in training loads on the playing performance of rugby league players are required.

\section{Author's affiliation}

T J Gabbett, Queensland Academy of Sport, QLD, Australia

Conflict of interest: none declared.

\section{REFERENCES}

1 Gabbett TJ. Physiological and anthropometric characteristics of amateur rugby league players. Br J Sports Med 2000;34:303-7.

2 Gabbett TJ. Physiological characteristics of junior and senior rugby league players. Br J Sports Med 2002;36:334-9.

3 Gabbett TJ. Influence of physiological characteristics on selection in a semi-professional rugby league team: a case study. J Sports Sci 2002;20:399-405.

4 Coutts A, Reaburn P, Abt G. Heart rate, blood lactate concentration and estimated energy expenditure in a semi-professional rugby league team during a match: a case study. J Sports Sci 2003;21:97-103.

5 Gissane C, Jennings DC, Standing P. Incidence of injury in rugby league football. Physiotherapy 1993;79:305-10.

6 Gissane C, Jennings D, White J, et al. Injury in summer rugby league football: the experiences of one club. Br J Sports Med 1998;32:149-52.

7 Gissane C, Jennings D, Kerr K, et al. A pooled data analysis of injury incidence in rugby league football. Sports Med 2002;32:21 1-6.

8 Brewer J, Davis J. Applied physiology of rugby league. Sports Med 1995;20:129-35

9 Meir R, Arthur D, Forrest M. Time and motion analysis of professional rugby league: a case study. Strength Cond Coach 1993;1:24-9.

10 Gissane $C$, Jennings $D$, Jennings $S$, et al. Physical collisions and injury rates in professional super league rugby. Cleve Clin J Med 2001;4:147-55.

11 Gibbs N. Injuries in professional rugby league: a three-year prospective study of the South Sydney professional rugby league club. Am J Sports Med 1993;21:696-700.

12 Hodgson Phillips L, Standen PJ, Batt ME. Effects of seasonal change in rugby league on the incidence of injury. Br J Sports Med 1998;32:144-8.

13 Gabbett TJ. Incidence, site, and nature of injuries in amateur rugby league over three consecutive seasons. Br J Sports Med 2000;34:98-103.

14 Gabbett TJ. Severity and cost of injuries in amateur rugby league: a case study. J Sports Sci 2001;19:341-7.

15 Gabbett TJ. Incidence of injury in semi-professional rugby league players. Br J Sports Med 2003;37:36-43.

16 Gissane C, Jennings DC, Cumine AJ, et al. Differences in the incidence of injury between rugby league forwards and backs. Aust J Sci Med Sport 1997;29:91-4.

17 Gabbett TJ. Training injuries in rugby league: an evaluation of skill-based conditioning games. J Strength Cond Res 2002;16:236-41.

18 Gabbett TJ. Influence of training and match intensity on injuries in rugby league. J Sports Sci 2004;22:409-17.

19 van Mechelen W, Hlobil H, Kemper HCG. Incidence, severity, aetiology and prevention of sports injuries. A review of concepts. Sports Med 1992; 14:82-99.

20 Ellis L, Gastin P, Lawrence S, et al. Protocols for the physiological assessment of team sport players. In: Gore CJ, ed. Physiological tests for elite athletes. Champaign, IL: Human Kinetics, 2000: 128-44.

21 Brewer J, Davis J, Kear J. A comparison of the physiological characteristics of rugby league forwards and backs. J Sports Sci 1994;12:158.

22 Australian Coaching Council. Multistage fitness test. A progressive shuttle-run test for the prediction of maximum oxygen uptake. ACT, Australia: Australian Sports Commission, 1988.

23 Ramsbottom R, Brewer J, Williams C. A progressive shuttle run test to estimate maximal oxygen uptake. Br J Sports Med 1988;22:141-4.

24 Foster C, Florhaug JA, Franklin J, et al. A new approach to monitoring exercise training. J Strength Cond Res 2001;15:109-15.

25 Orchard J, Seward H, McGivern J, et al. Rainfall, evaporation and the risk of non-contact anterior cruciate ligament injury in the Australian Football League. Med J Aust 1999; 170:304-6.

26 Hopkins WG. Probabilities of clinical or practical significance. Sportscience 2002;6:sportsci.org/jour/0201/wghprob.htm.

27 McArdle WD, Katch FI, Katch VL. Exercise physiology. Energy, nutrition, and human performance. Baltimore, MD: Williams and Wilkins, 1996.

28 Brukner P, Khan K. Clinical sports medicine. Sydney: McGraw-Hill, 1994.

29 Fry RW, Morton AR, Keast D. Overtraining in athletes. An update. Sports Med $1991 ; 12: 32-65$.

30 Orchard JW. Intrinsic and extrinsic risk factors for muscle strains in Australian football. Am J Sports Med 2001;29:300-3.

31 Turbeville SD, Cowan LD, Asal NR, et al. Risk factors for injury in middle school football players. Am J Sports Med 2003;31:276-81.

32 Holmyard DJ, Hazeldine RJ. Seasonal variations in the anthropometric and physiological characteristics of international rugby union players. In: Reilly T, Clarys J, Stibbe A, eds. Science and football II. Proceedings of the Second World Congress of Science and Football. London: E\&FN Spon, 1993:21-6.

33 Tong RJ, Mayes R. The effect of pre-season training on the physiological characteristics of international rugby players. In: Reilly T, Bangsbo J, Hughes M, eds. Science and football III. Proceedings of the Third World Congress of Science and Football. London: E\&FN Spon, 1997:98-102.

34 Mercer TH, Gleeson NP, Mitchell J. Fitness profiles of professional soccer players before and after pre-season conditioning. In: Reilly T, Bangsbo J, Hughes M, eds. Science and football III. Proceedings of the Third World Congress of Science and Football. London: E\&FN Spon, 1997:112-7. 